\title{
Open field behavior of the Mongolian gerbil ${ }^{1}$
}

DENNIS J. NAUMAN UNIVERSITY OF KANSAS

Mongolian gerbils and albino rats were observed individually in an open field. The rats exhibited their normal tendency to remain in the peripheral areas of the field. However, the gerbils did not show such thigmotactic tendencies. Gerbils demonstrated more frequent central area occupancy, greater duration of central area occupancy, and greater locomotion in the field. The greater alertness and activity of the gerbil, in combination with its apparent relative preference for an open field, may have important implications in maze running situations.

This note points out an unusual aspect of the open field running behavior of the Mongolian gerbil, Meriones unguiculatus.

The gerbil has previously come to the attention of researchers primarily through its use in metabolic and cholesterol ingestion studies (Clarkson, King, \& Warnock, 1957; Gordon, Cekleniak, Stolizenberg, Benitz, \& Moraski, 1961; Robinson 1959; Winkelman \& Getz, 1962). However, Tanimoto (1943) described its natural habitat and general behavioral characteristics and provided a physical description, Walters, Pearl, \& Rogers (1963) reported two short experiments on exploratory and avoidance behavior, and Nauman (1962) investigated aspects of its social behavior. Nauman has also made available a mimeographed summary of the pre-1963 literature employing Meriones unguiculatus, along with a statement of preliminary behavioral investigations of the species. ${ }^{2}$

The thigmotactic or stereotropic tendencies of the white rat, particularly in open field situations, have long been a topic of experimentation and speculation. Crozier \& Pincus (1926) found that young rats manifest a typical stereotropic orientation toward a lateral surface of contact. Several studies of relevance were cited in Maier \& Schneirla (1935), some of them concerned with the influence of this tendency upon maze running and learning. A somewhat analogous series of studies are those on kinesthesis and maze running. More recently, Mead (1960) and Stackhouse, Burns, \& Wahlford (1960) have discussed the tendency of the rat to remain near the walls or in the periphery of an enclosed open field. The present note contrasts these behaviors with that of the Mongolian gerbil.

Methad

The Ss were 15 Mongolian gerbils, Meriones unguiculatus, approximately three months of age, and 15 young adult white rats. No sex discriminations were made and all animals were experimentally naive.

The open field measured $3.5 \times 3.5 \mathrm{ft}$ and was surrounded by a $1.5 \mathrm{ft}$ high sheet metal wall. The field was sectioned into $496 \times 6$ in. squares. These squares were grouped into three concentric rings with areas as follows: inside $18.4 \%$, intermediate $32.6 \%$, and outside $49 \%$ of the total field area.

\section{Procedure}

During two trials (on consecutive days), each of $1 \mathrm{~min}$ duration, 15 gerbils and 15 rats were observed individually in the field. Each $S$ was placed in the center of the field and at $1 \mathrm{sec}$ intervals its location, in terms of the concentric rings, was recorded by use of a stenograph recorder (Heimstra \& Davis, 1962). Simultaneously, the S's path was traced on a scaled mimeographed copy of the field. This scaled path was measured and the data was transformed appropriately to determine the distance traveled during each trial. The duration of occupation of each of the three rings was computed for each $\mathrm{S}$ by summing across both trials. These figures were then expressed as percentages of each S's total observation time (2 $\mathrm{min}$ ).

\section{Results and Discussion}

Averaging the individual percentages within species, the interspecies comparison for area occupation durations and for total distances traversed were as presented in Table 1. The magnitude of the differences between means, as compared to the size of the standard deviations, renders statistical analysis unnecessary.

Thus, while the rats demonstrated the usual wallhugging response in the open field, the gerbils did not show this tendency to remain near the walls, and in fact appear to have spent a disproportionate amount of time in the central areas. The greater activity level of the gerbil is demonstrated by the discrepancy in the distances traveled during $1 \mathrm{~min}$ of observation. The present findings are not inconsistent with those of Walters et al (1963) indicating that "... exploratory behavior increased with size of the test area" (as measured by latencies in entering the test area), and may imply support of their inference of a gerbil "preference" for an open field environment.

The tendency of the gerbil to traverse the center of the field is illustrated by comparing Figs. 1 and 2, which represent typical patterns of gerbil and rat Table 1. Average percentages of total observation time $(2 \mathrm{~min})$ spent within each concentric area of the open field by gerbils and by rats, and respective distances traveled per $\mathrm{min}$.

\begin{tabular}{|c|c|c|c|c|}
\hline \multirow[b]{2}{*}{ Time spent in } & \multicolumn{2}{|c|}{ Gerbil } & \multicolumn{2}{|c|}{ Rat } \\
\hline & $\overline{\mathrm{X}}$ & s & $\bar{x}$ & s \\
\hline Inside $18 \%$ & $35 \%$ & 10.54 & $9 \%$ & 3.97 \\
\hline Intermediate $33 \%$ & $28 \%$ & 6.63 & $5 \%$ & 5.12 \\
\hline Outside $49 \%$ & $37 \%$ & 6.95 & $86 \%$ & 7.65 \\
\hline $\begin{array}{l}\text { Distance traveled } \\
\text { per min }\end{array}$ & 396 in & & $190 \mathrm{i}$ & \\
\hline
\end{tabular}




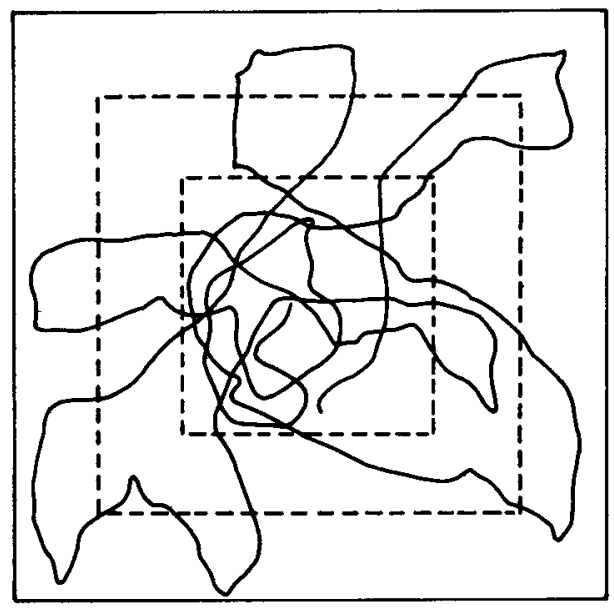

Fig. 1. Typical pattern of locomotion in the open field for $M$. unguiculatus. Duration of run equal $1 \mathrm{~min}$.

locomotion in the field. These patterns are not necessarily an accurate indication of duration spent in any particular area. For example, a good portion of the $9 \%$ central area occupation of the rat was due to the Ss' immobility following initial center placement, while the gerbil massed its $35 \%$ primarily by recurrent runs to the center. These differential patterns of mobility can be further described by indicating that the gerbils entered the peripheral ring an average of 6.63 times per min, while the rats entered the outer ring only 1.46 times per min.

On the second trial the rats appeared to move a bit more freely throughout the field, and on this second observation the average rat ran approximately $30 \mathrm{in}$. farther than on the first trial. However, because a greater degree of locomotion (per observation period) indicates a greater rate of speed, more frequent entering of the center area does not imply a greater duration of occupation of that area. In fact, the duration of center area occupation declined (by $49 \%$ ) on the second observation for the rats. The resultant "time residual" was consumed entirely by an equivalent increase in duration of peripheral area (the outside ring) occupation. Distances traveled and area occupation durations did not vary substantially across observation periods for the gerbils.

The behavior of the gerbil could not be typified as "wall-avoidance," for oblique entrances to and exits from the outer area were common enough. There was merely no strong tendency to run parallel and proximate to these surfaces.

Some of the more obvious implications of the present findings would be relevant to maze running, for it is possible that the gerbil will behave quite differently

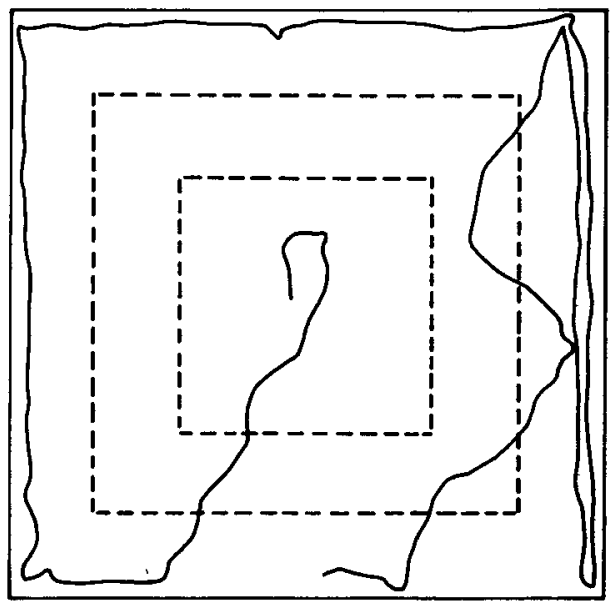

Fig. 2. Typical pattern of locomotion in the open field for the white rat. Duration of run equal $1 \mathrm{~min}$.

than the rat in maze and runway situations in which the lateral surfaces evidently attract the rat to contact or proximal relationships.

\section{References}

CLARKSON, T. B., KING, J. S. JR., \& WARNOCK, N. H. Serum and tissue cholesterol levels of cholesterol-fat-fed gerbils. Proc. Animal Care Panel, 1957, 7, 220-221.

CROZIER, W. J., \& PINCUS, G. Sterotropism in rats and mice. J. gen. Physiol., 1926, 19, 195-203.

GORDON, S., CEKLENIAK, W. P., STOLZENBERG, S. J., BENITZ, K., \& MORASKI, R. M. Biochemical and morphological effects of cholesterol and its methyl ether in the gerbil. Toxicol. \& appl. Pharmacol, 1961, 3, 315-334.

HEIMSTRA, N. W., \& DAVIS, R. T. A simple recording system for the direct observation technique. Anim. Behav., 1962, 19, 208-210.

MAIER, N. R. F., \& SCHNEIRLA, T. C. Principles of animal psychology. New York: McGraw-Hill, 1935.

MEAD, A. P. A quantitative method for the analysis of exploratory behavior in the rat. Anim. Behav., 1960, 8, 19-31.

NAUMAN, D. J. The effects of recent social isolation upon stbsequent social behavior in the Mongolian gerbil. Unpublished M. A. thesis, University of South Dakota, 1962.

ROBINSON, R. F. Metabolism of the gerbil, Meriones unguiculatus, Science, 1959, 130, 502-503.

STACKHOUSE, S. P., BURNS, N. M., \& WAHLFORD, JOANN. Note on exploratory behavior. Psychol. Rep., 1960, 6, 455-457.

TANIMOTO, K. Studies on mammals in relation to bubonic plague in Manchuria, Part 3. Zool. Mag. Tokyo, 1943, 55, 117-127 (Jap.)

WALTERS, G. C., PEARL, J., \& ROGERS, J. V. The gerbil as a subject in behavioral research. Psychol. Rep., 1963, 12, 315-318.

WINKELMAN, J. R., \& GETZ, L. L. Water balance in the Mongolian gerbil. J. Mammal., 1962, 43(2), 150-154.

Note

1. Investigation conducted in 1962 at University of South Dakota under the support of N. S. F. Undergraduate Scientific Education NSF G21682.

2. Copies of "Statement of preliminary investigation and observation of the Mongolian gerbil Meriones unguiculatus" are available from the author, Department of Psychology, University of Kansas, Lawrence, Kansas, 66044. 